\title{
Legal Protection of Copyright Items Inheritance in the Internet by Means of a Creative Commons License
}

\author{
Yelena Anatolyevna Kirillova ${ }^{1}$, Marina Vladimirovna Vasiljeva ${ }^{2} \&$ Yulia Aleksandrovna Krohina ${ }^{3}$ \\ ${ }^{1}$ South-west state university, 305040, Kursk, st.50 years of October 94, Kursk, Russian Federation \\ ${ }^{2}$ Publishing House "Scientific review", Moscow, Russian Federation \\ ${ }^{3}$ Financial University under the Government of the Russian Federation, Moscow, Russian Federation \\ Correspondence: Marina Vladimirovna Vasiljeva, Publishing House "Scientific review”, Moscow, Russian \\ Federation. E-mail: marinavv2010@mail.ru
}

Received: October 18, 2014 Accepted: November 11, 2014 Online Published: November 15, 2014

doi: $10.5539 /$ res.v6n4p232

URL: http://dx.doi.org/10.5539/res.v6n4p232

\begin{abstract}
In this paper, we consider legal protection of copyright items in the Internet. The subject of the research is copyright protection of potential heirs on the Internet with the help of modern computer technologies. The purpose of the research is development of a system for copyright protection on the Internet in the case of inheritance. Use of copyright protected intellectual property in computer networks positively differs from any known types of copyright item use, including over-the-air transmission or a message for universal information across the wire. This is due to information physical properties change within digital media, new law features and properties of intellectual product as an object of legal relationship appear, emerges brand new system of public relations, connected with high technology application suggesting copyright dualism. In spite of this fact, many researches propose to inherit works of authorship posted in the Internet in a traditional way by means of will or law. This can be explained by a relatively narrow approach to the understanding of copyright. This understanding is based on the current beliefs about it solely as about an institution of civil law. We believe it necessary to abandon the industry isolationism and, instead, use an integrated approach in the scientific search on the problems of copyright protection on the Internet, and to see the concept of copyright as a complex one at the intersection of different branches of law. The development of modern, including computer technologies exacerbates the problem of protecting the rights of creators of literary, artistic, and scientific works. We propose new approach applicable only to digitized works published in the Internet. For this reason it is necessary to legalize heirship in international free and constrained licenses of Creative Commons and alike, in case of the testator's death, through specifying a potential heir in the will at that (electronic testament). We also propose legislating the electronic form of work as an objective form of expression in international conventions, contracts, and agreements in the area of copyright protection, what will make it possible to give equal rights to printed and electronic copies.
\end{abstract}

Keywords: heir, testator, digitized work, digital media

\section{Introduction}

Intellectual property is one of the key concepts of the international community of beginning of the XXI century. Modern conditions of the world facilitate the growing influence of the intellectual factor on the economic, social, and political development. In order to create favourable conditions for accumulating the intellectual potential of society, the law guarantees freedom of literary, artistic, scientific, technical, and other forms of creativity to every person. This freedom gets specific legal guarantees in the form of copyright. The rapid development of information technologies and their wide application in all the countries is a social phenomenon called "information revolution" (Arias \& Cameron, 2013). Society has refused material copies of work in connection with shift towards turnover of works in digital form. Works in digital form are the works allocated in the Internet and recorded to electronic media (digitized works). Under the new conditions, the traditional system of copyright is being rapidly displaced by the system of digitized works presented in open access in the Internet (Ficsor, 2002). The developing technologies and the scale of exchange of copyright information in the Internet led to the situation when efficiency of legal provisions had significantly reduced. As many experts fairly note such provisions initially were not designed for regulation of relations linked with use of digital media (Balganesh, 
2011). Thus, the problem of free copying and spreading of copyright items in the Internet produces intractable collisions - for example, the addressing to work allocated on site is, in fact, the copying of this work to user's server, what automatically leads to copyright infringement. Besides, according to statistics, users do not estimate illegal copying in the Internet as an offense. Such an opinion was given by $78 \%$ of Internet users in USA (Dinah, 2009).

At the same time, the Internet has some unique properties - among them, there are transboundary, interactivity and unity. All these demand complex international approach to elaboration of legal model of author's rights inheritance protection in the Internet (Deyneko, 2013). In view of the novelty of the Internet relationship, legal, logical, and normative analysis shall be used to identify the value of the common law categories in the implementation of guarantees of the rights fir creators of literary, artistic, and scientific works.

The matter of inheritance of copyright items allocated in the Internet becomes increasingly actual, as with time heirs of sites, computer programs and digitized works appear (103rd Congress, 2nd session, 1994). Formalizing the guarantees for creators of literary, scientific, and artistic works, copyright acts as one of the most important structural elements of the democratic system of the state for the implementation of the rights and freedoms of a human being and a citizen. However, researchers addressing to the theme of copyright items Internet use (WiUiam, 2012; Anthony, 2008; Lynne, 1992; Varian, 2000; Samuelson \& Wheatland, 2009) hardly touch upon the subjects of digitized works inheritance and heirs and testators' rights.

The use of intellectual activity results in the Internet is a rapidly developing part of economy (Internet, 1996). Our intellect has gradually become one of the most important factors of social production, and the works of man's reason or "intellectual capital" —one of the main objects of economic turnover (Knowledge Management, 2001).

\section{Legal status of Digitized Works}

The constantly growing volume of digitized works on the Internet requires a change in the legal implementation of the copyright. Based on the study of general methodological, general theoretical works and developments of leading legalists, and special works on copyright and intellectual property rights, it shall be noted that the fundamental value is given to the identification of the role of the general legal principles and categories, such as individual rights, individual freedom, freedom of creativity, the object and the subject of copyright on the Internet. The constantly growing volume of digitized works in the Internet requires the change of legal model of copyright realization. As researchers say (Towse, 2013), the necessity for revision of copyright law has become even more actual in the last several years. In such a respect the following aspects should be recognized: the genuine work can exist in objective form on machine-readable storage medium; the storage medium is presented with magnetic or optical disk and used by computer for data recording, storing and reproduction; the work should be presented in the form of file or set of files what is being an expression of work in objective form; physically the genuine work can be initially recorded to the computer's storage media used by the author, or to generally available public computer (Kobylyatsky, 2010).

The differences are obvious insomuch that many lawyers ask whether the publication of work in the Internet is being a manifestation, as legislator understands it (Merrill \& Smith, 2001). The author's right to manifest his work implies the right to perform an action or to give consent to perform an action, which for the first time makes the work available for general public by means of radio, cable, publishing, public performance, public view or in any other way. In connection with it, we should develop and legislate the special electronic form of work manifestation in the Internet. Thus, the fact of availability of access to the work on storage media used by computer will be estimated as its manifestation.

Many experts considering judicial practice on disputes over copyright in the Internet note that "there is a need of further development in the frames of DMCA for purposes of increasing of conformity in respect of work of authorship licensing with due consideration of cyberspace" (Dorrain, 2014).

Many researches aimed at studying of authors' rights and copyright holders' protection mechanisms were held in different countries all over the world (Karla, 2009). Therewith, empirical studies cover three branches: the protection of copyrights from unauthorized use of work (Jennifer, 2010), the profit from works of authorship (Copenhagen Economics, 2010) and free (non-commercial) use of copyright items (Dinusha, 2013).

"The copyright in digital media is considered as the process where there is a need of balancing author's interests toward profit earning with the interests of consumers who claim for availability of art products" (Juile, 2007). Thus, a democratic approach will be considered. The approach is based on the modern concept of law, which develops the essence of copyright of the natural world of human rights and social justice. 
The problem of heirs of digitized works remains actual and poorly studied—we have found no major researches dedicated to this subject. Computerization in the field of copyright is a difficult and complex problem that must be solved, taking into account the variety of legal, social, organizational, and technical factors. The problem of protecting the rights of creators of literary, artistic, and scientific works faces with such important natural rights of a human being, as personal integrity, freedom of speech, of thought, the right to enjoy culture, and to have access to informational resources. Legal science is facing a challenge of the ratio of public and private interest in the field of intellectual creativity, of the limits of freedom for exercising the rights in the field of culture and information - the rights of creators of literary, scientific, and artistic works, and every citizen, every personality.

As a rule, researchers dealing with it hold a view that digitized works can be also inherited by will or by law, as traditional works are inherited (Craig, 2009). Being agreed with this opinion, we nevertheless should state that at inheritance of works allocated in the Internet there can be definite problems. A brand new system of social relations emerged. The system is associated with the use of modern technologies and, in most cases, when disputes of various kinds require broad interpretation of the law, because the law lacks the necessary references to the specifics of copyright protection on the Internet. If a testator makes his will and inform potential heirs of access codes to resources where there are his works allocated, the right to inherit in such a case will be protected at most. In such a situation, heirs will be able to use incomes produced by the work, if it was allocated for the purpose of commercial profit. In addition, they can proceed the work at testator's site and finish some other author's projects in case he had made such a will. However, there is no way of drawing up a digital electronic will-researchers do not even consider such a possibility. At the same time, we can suppose if there is an opportunity of digital signing, electronic document flow, and commercial digitized works' registration systems, sooner or later such a matter will arise.

However, if there is no testament, many questions appear: how the rights of heirs of works allocated in the Internet will be protected; what property and non-property rights the heirs will gain; will the heirs able to use profit from intellectual property if it was allocated in digital media for the purpose of commercial profit? Another one important matter is the period of digitized work protection after the author's death.

\section{Copyright protection with help of Creative Commons licenses}

With development of the Internet, we have got the opportunity of works' creation in digital format as well as of digitization of traditional works of authorship (Dorfman, A., 2010). As a rule, "the copyright items are the works of science, literature and art" (Dane, 2002) regardless of their advantages, purpose and the way of its expression. As we can see from this definition, this list does not include sites, software, databases, and electronic books yet (US Senate, 2008).

Taking into account such circumstances, Creative Commons, the non-commercial organization, has made free-for-use standard contracts - free and non-free public licenses. With help of these licenses, authors and copyright holders can express their will and distribute their works in wider and freer way, while consumers gain opportunity of using these works in legal and quite simple way (Paley, 2010). The legal status of digitized works should comprise effective mechanism of copyright items transfer and distribution. The copyright holders at that can determine the onerousness of rights transfer and the ways of intellectual property disposition, i.a. in case of death (Biyle, n.d.). Since the advent of digital and network technologies, there are new trends and problems defined with the following circumstances:

- the concept of work's material copy, which previously was a basis for copyright, has dwindled under the modern conditions of digital media;

- to regulate relations in the area of copyright protection new concept was introduced: "the public dissemination of work in such a way, when any person can get access to work...". Thus, the idea of access becomes more important concept than copying and distribution in paper medium (CC Affiliate Network);

- existing informational space has become even more transboundary with the advent of cloud computing, at which resources are performed to user as Internet-service (Mako, 2005).

The aim of Creative Commons is to allow authors of digitized works allocated in the Internet to transfer some of their rights to users and at the same time "to reserve definite right" (Klass, 2008). Creative Commons tends to support the formation of richer public domain, offering alternative to automatic copyright on the principle of "all rights reserved" (Rowlands, M., 2011) by the principle of "some rights reserved" (Broussard, S. L.).

In licenses of Creative Commons the conditions of licenses are prescribed right in their titles (for example, the license, in accordance with which one can use work for non-commercial purposes under the condition of author attribution, is called "Attribution-Noncommercial"). The conditions of licenses are prescribed in the form of 
"license elements" combination. At that, each element also possesses its own designation in the form of picture. We can see it in the following table 1 .

Table 1. The conditions of licenses

\begin{tabular}{ll}
\hline Attribution (briefly - BY) & User must attribute the author of the work. \\
\hline Share-alike (briefly - SA) & $\begin{array}{l}\text { Derivative works must be obligatory spread under the } \\
\text { conditions of this license. }\end{array}$ \\
\hline Non-commercial (briefly - NC) & $\begin{array}{l}\text { It is prohibited to use the work for the purposes of profit } \\
\text { earning. }\end{array}$ \\
\hline No Derivative Works (briefly - ND) & $\begin{array}{l}\text { It is prohibited to create derivative works on the basis of } \\
\text { this work. }\end{array}$ \\
\hline
\end{tabular}

The following conditions of licenses are informal; they can be easily puzzled out by authors as well as by users. The creator of Creative Commons, Lawrence Lessig (Lessig, 2007), calls them "human readable". However, they do not stand good in law, and that is why the correct "lawyer readable" formulations are articulated for each of them. Thus, the system of licenses is being quite convenient for users and lawyers. Authors can choose a CC Attribution License in case when it does not matter for them what people will do with their works as long as they attribute authorship (Stallman, 2012). From the business point of view, the works under CC Attribution present the perfect opportunity of taking the work made by other people to make some insignificant alterations in it and produce on its basis a derivative work. Thus, it will be undivided intellectual property of the company and can be used for the commercial purposes. "The derivative work implies some contribution into original material for the purpose of its transformation" (Melville, 2013).

CC Attribution-Share Alike (briefly-CC-BY-SA) - the license "with designation of authorship and conditions reservation" (David, S. V., 2013). This is the most popular license. It allows others to process, improve and develop work even for the commercial purposes under the conditions of authorship attribution and derivative works licensing. The present license is being a copyleft license (Shyamkrishna, 2012).

The judicial proceedings concerning licenses of Creative Commons are held rather seldom. Although Creative Commons has been existing for about ten years and hundreds millions of works of art were published under its licenses.

Creative Commons considers the absence of judicial proceedings is an evidence of wide recognition and accessibility of their licenses (SGAE v. Fernandez, n.d.). Nevertheless, Creative Commons appreciates decisions of courts confirming their licenses function just as they should function. Let us review a legal case. In the end of 2005 the Spanish Society of Collective Rights Management (Sociedad General de Autores y Editores) filed a lawsuit against a bar owner, insisting he had not paid licensing fee necessary for public execution of music for three years. The court dismissed complaints of SGAE, as the owner of bar had proved the music played in his bar was licensed by musicians by means of Creative Commons licenses. Consequently, SGAE had no right to demand provisions for licensing fees (Curry v. Audax, n.d.). The licenses of Creative Commons reserve author's copyrights (Newman, 2013), however, we should note that the rights of heirs as of potential copyright holders are not accommodated in the present license.

\section{The Rights of Heirs of Digitized Works}

A copyright is devolved. The protection of works' integrity after author's death is performed by his heirs and by the organizations responsible for copyrights protection. In cases of use of a work without an agreement with author or subsequent proprietors (heirs), violation of conditions of a work without author's consent, or in case of violation of work's integrity or other personal non-property rights, the author (or his heirs) has a right to demand for violated right recovery (Cariou \& Prince, 2013).

Author's heirs are represented with a special group of subsequent proprietors, to whom the government provides the opportunity of protecting rights for the work developed by testator (Nordemann, Czychowski, \& Gruter, 1998). The heirs are the subjects of derivative right, who perform authority of property right. The personal non-property authority, such as right on name, right of authorship, right to reputation protection, is not devolved. 
In scientific legal literature, the copyright and law of inheritance received much criticism as there was no distinct regulation of copyright items' inheritance in digital media.

Taking into account the fact that many works allocated in the Internet produce a good profit for authors and copyright holders, we MUST talk about heirs' property rights (Payne, 1999). The main source of wealth today is not financial resources, but intellectual capital and knowledge/technologies based on it (John \& Zipursky, 2010). Besides, modern license agreements provide an opportunity of commercial use of digitized works (Briat, 1998). Considering digitization of works allocated in the Internet and major use of Creative Commons licenses, it is rather reasonably to prescribe in these licenses the rights of potential heirs - the copyright holders.

We should also note that the principle of extraterritoriality in international copyright protection practice during jurisdiction establishment must be used in respect of works allocated in the Internet. Such an opinion was given by European researchers (Bern Convention, 1886), and to our mind, the principle of extraterritoriality is applied to the matters of inheritance.

\section{Conclusions}

Having studied the matters of digitized works inheritance legal protection trends, we have drown the following conclusions:

\section{Theoretical:}

1) The copyright in digital media is at the intersection of civil, computer, information, constitutional, and labour law, sociology, political science, and economics; has own set of public relations that differs from the set of relations formed in traditional copyright, which deals with things as with physical carriers of works and defines works as production. The right of authorship in digital media possesses its principles, methods, matter, developing legal framework - and that is why the legal methods of copyrights protection should consider the specific character of digital media. The expansion of legal framework of copyrights for performance of possibility to act under the conditions of new digital media leads us to the conclusion about dualism of copyright in the modern context.

2) Copyright in the digital environment is a complex system of legal norms regulating social relations in the information and communications environment between the author or the copyright owner, information broker, and the consumer, which are related to the circulation of information, formation and use of information resources, establishment and operation of information systems in order to provide safe meeting the information needs of citizens, organizations, government, and society.

3) A digital testament to the digitized work shall mean a private disposition of the copyright belonging to the citizen in case of the death, committed within the framework of the license used by the author on the Internet.

\section{Practical:}

4) We propose to prescribe the rights of potential heirs in licenses of Creative Commons or some analogous ones.

It can be done using a graphic element, for example, as the following- 1 . Thus, considering the conditions of license and its attitude towards free or non-free access, heirs will be able to administer property rights on digital work allocated in Internet.

5) It is necessary to give a testator an opportunity of preliminarily administering the rights on digitized work in contemplation of death by designation in Creative Commons or analogous licenses of potential heir (the electronic testament), for example, Ivanov V.V. 08.08.2008 and other data. Thus, the heirship will be protected in suitable way even in case of judicial disputes.

\begin{tabular}{lll}
\hline & Attribution (briefly - BY) & User must attribute the author of the work. \\
\hline 10 & Protection of the rights of heirs (briefly - PH) & Protection of heirs' rights. \\
\hline Share-alike (briefly - SA) & $\begin{array}{l}\text { Derivative works must be obligatory spread } \\
\text { under the conditions of this license. }\end{array}$ \\
\hline
\end{tabular}


Non-commercial (briefly - NC)

No Derivative Works (briefly ND)
It is prohibited to use the work for the purposes of profit earning.

It is prohibited to create derivative works on the basis of this work.

6) It would be reasonable to link the concept of "publication of work" with relations in the Internet, where under publication we can consider the allocation of one electronic copy performing commercial or free access to it for users in the Internet. In addition, the legislative protection should cover not only the works fixed in one or another material form, but also the works in digital form. To do this we should confirm in all the convention, contracts, and agreements concerning copyright protection the electronic form of work as an objective form of expression, what will help to give equal rights to printed and electronic copies.

\section{References}

Arias J. J., \& Cameron E. (2013). The decreasing excludability of digital music implications for copyright. Arias Cameron American Economist, 58(2), 124.

Berne Convention on protection of literary and art works. (1886). International Agreements Bulletin, No. 9. C.3.

Briat, M. (1998). Personal data and the free flow of information. In Freedom of data flows and ECC law (pp. 45-57).

Broussard, S. L. (2007). The copyleft movement: Creative commons licensing Communication Research Trends.

Cariou \& Prince. (2013). Copyrightlaw-Fair-second circuitholds that appropriation artwork need not comment on the original to be transformative.

CC Affiliate Network - CC Wiki. http://wiki.creativecommons.org/CC_Affiliate_Network

Copenhagen Economics. (2010). Economic impact of a European digital single market, commissioned by European Policy Centre. Retrieved April 23, 2013, from http://www.epc.eu/dsm/2/Study_by_Copenhagen.pdf

Curry \& Audax. Creative Commons. http://wiki.creativecommons.org/Curry_v._Audax

David, S. W. M. (2013). Right to integrity and the proposed resale royalty right and Notification right and the PRC copyright Law. Science and Technology.

Deyneko, A. (2013). Civil-law regulation of bringing products to the public with the use of information and telecommunication networks in the Russian Federation. Moscow.

Dinah, A. (2009). Downloadable Music Set Free: The Flip Side of DRM Protection (p. 230). Duke University.

Dinusha, M. (2013). Digital Economy Act 2010. Why the 'three strikes' law is not the answer to copyright law's latest challenge, International Review of Law. Computers \& Technology, 27(1-2), 60-84. http://dx.doi.org/10.1080/13600869.2013.764137

Dorfman, A. (2010). Can Tort Law Be Moral. 23 RATIO JURIS, 205, 205-206. http://dx.doi.org/10.1111/j.1467-9337.2010.00451.x

Dorrain, K. F. (2014). A Survey of Developments in Copyright Law: A Perspective from Cyberspace. Report Information from ProQuest.

Ficsor, V. (2002). The law of Copyright and the Internet: The WIPO Treaties and Their Implementation (p. 750). Oxford University Press.

Internet security: Hearing before the Subcommon science of the Common science, space, a. technology. (1994). US House of representatives. Washington, Gov. print.

Internet tax trade issues: Hearing before the Comm. on finance, US Senate. (1998). 105th Congress. Washington.

Internet. (1996). A new medium: Mew legal issues: Report of an interdepartmental Working Party on penal, data protection and copyright aspects of the Internet. Federal Office of Justice. Bern, IV.

Jennifer, E. (2010). Rothman, Liberating Copyright: Thinking Beyond Free Speech. 95 CORNELL L. REV., 463.

John, C. P., \& Zipursky, C. (2010). Goldberg \& Benjamin. Torts as Wrongs. 88 TEX. L. REV., 917, 945-46.

Julie, E. (2007). Cohen, Creativity and Culture in Copyright Theory. 40 U.C. DAVIS L. REV, 1151. 
Karla, M. (2009). Downloading Personhood: A Hegelian Theory of Copyright Law. 7 CAN. J.L. \& TECH.

Klass, G. (2008). Three Pictures of Contract: Duty, Power, and Compound Rule. 83 N.Y.U. L. REV, 1726, 1741-1742.

Knowledge Management. (2001). A state of the art guide. Models and tools, strategy, intellectual capital, planning, learning, culture, processes (p. 7). Paul R. Gamble and John Blackwell.

Kobylyatsky, D. A. (2014). Verification of the author's right to a work on the Internet. Retrieved February 12, 2014, from http://www.juristlib.ru/book_9989.html

Lessig, L. (2007). Free Culture. How Big Media Uses Technology and the Law to Lock Down Culture and Control Creativity. The Pegnum Press.

Lynne, A. (1992). Greenberg, The AH of Appropriation: Puppies, Piracy, and Post-Modemism. I I CARDOZO A $R T S \& E N T$. L.J. I, 29.

Mako, H. B. (2005).Towards a Standard of Freedom: Creative Commons and the Free Software Movement.

Melville, B. (2013). Nimmer \& David Nimmer, Nimmer on copyright.

Newman. (2013). The Danger of Using Creative Commons Flickr Photos in Presentations. Librarian by Day.

Nordemann, J. B., Czychowski, C., \& Gruter, A. W. (1998). The Internet, the name server and antitrust law. European competition law review, 19(2), 99-105.

Paley, N. Creative Commons Branding Confusion. Techdirt. (2010). http://www.techdirt.com/articles/20101020/09352711499/creative-commons-branding-confusion.shtml

Payne, A. (1999). Domain Names, Trade Marks and Unfair Competition. In A Practioner's Guide to the Regulation of the Internet (pp. 9-66). London.

Reese, A. (2008). Transformativeness and the Derivative Work Right. 31 COLUM. J.L. \& A R T S, 467.

Rowlands, M. (2011). UK: Internet censorship looms as government finds alternative to flawed Digital Economy Act. Retrieved September 7, 2011, from http://www.statewatch. org/analyses/no-147-internet-censorship.pdf

Samuelson, P. (2009). Tara Wheatland, Statutory Damages in Copyright Law: A Remedy in Need of Reform. 51 WM. \& MARY L. R E V, 439, 449.

Shyamkrishna B. (2012). The Normativity of copying in copyright law. Duke law journal. Chang v. Virgin Mobile. Creative Commons.

Shyamkrishna, B. (2011). The obligatory structure of copyright law: The Normativity of Private Law. 31 O.J.L.S, 215.

Stallman, R. (2012). On-line education is using a flawed Creative Commons license. Retrieved from http://stallman.org/articles/online-education.html

Thomas W. M., \& Henry E. S. (2001). The Property Contact. 101 COLUM L. Rev, 773, 827-828.

Towse, R. (2013). The quest for evidence on the economic effects of copyright law. Cambridge Journal of Economics, 37, 1187-1202. http://dx.doi.org/10.1093/cje/bet014

Varian, H. R. (2000). Buyining, Sharing and information Goods. Jornal of Industrial economics, 49(1), 63-90.

WiUiam, W. (2012). Fisher III et al. Reflections on the Hope Poster Case. 2S HARV. J.L. \& TECH, 243, 321-322.

\section{Copyrights}

Copyright for this article is retained by the authors, with first publication rights granted to the journal.

This is an open-access article distributed under the terms and conditions of the Creative Commons Attribution license (http://creativecommons.org/licenses/by/3.0/). 